\title{
Diagnostic errors in an accident and emergency department
}

\author{
H R Guly
}

\begin{abstract}
Objectives-To describe the diagnostic errors occurring in a busy district general hospital accident and emergency (A\&E) department over four years.

Method-All diagnostic errors discovered by or notified to one $A \& E$ consultant were noted on a computerised database.

Results-953 diagnostic errors were noted in 934 patients. Altogether $79.7 \%$ were missed fractures. The most common reasons for error were misreading radiographs $(77.8 \%)$ and failure to perform radiography $(13.4 \%)$. The majority of errors were made by SHOs. Twenty two diagnostic errors resulted in complaints and legal actions and three patients who had a diagnostic error made, later died. Conclusions-Good clinical skills are essential. Most abnormalities missed on radiograph were not difficult to diagnose. Junior doctors in A\&E should receive specific training and be tested on their ability to interpret radiographs correctly before being allowed to work unsupervised.

(Emerg Med f 2001;18:263-269)
\end{abstract}

Keywords: radiography; diagnostic errors

Diagnostic errors are important in all branches of medicine as they are an indication of poor patient care. Medically, the significance of a diagnostic error in an accident and emergency (A\&E) department varies from minimal (for example, a fracture of the terminal phalanx) to potentially life threatening (for example, a missed myocardial infarction). In other patients a delay in diagnosis may lead to less good long term results (for example, tendon injury), increased operative risks (for example, femoral neck fracture) and pain and suffering until the injury is diagnosed. However, all errors have implications for patient care as even if the medical consequences of an error are minimal, patients are often distressed that an error has been made and this may cause difficulty in their relationship with the doctor or hospital. There may also be costs to the hospital. In particular, diagnostic errors may bring complaints, bad publicity and medicolegal costs.

The main reason for studying medical errors Emergency Department, Derriford Hospital, Plymouth PL6 8DH, UK

Correspondence to: Dr Guly

(henry.guly@phnt.swest.nhs.uk)

Accepted for publication 19 July 2000 causes of complaint and legal action against A\&E departments. ${ }^{2}$ Research into "medical accidents" (of which diagnostic errors are one type) has been neglected and the problem should be studied. " "Studies on the epidemiology of malpractice are just as important as studies of the epidemiology of disease . . .(as) they allow insights into the causative factors and ways of reducing the harm". ${ }^{3}$

A\&E departments are often staffed by very junior doctors. Errors are not uncommon and $\mathrm{A} \& \mathrm{E}$ is accepted as a "high risk" specialty. Most of what is written about diagnostic errors in $A \& E$ is in the form of case reports or diagnostic difficulties with specific injuries (for example, dislocated lunate, ${ }^{4}$ carpometacarpal dislocations, ${ }^{5}$ tendon injuries $\left.{ }^{6}\right)$. Diagnostic errors in patients with major injuries are described in papers describing management errors and deaths in such patients. ${ }^{7}$ Papers describing errors over a period of time usually describe the misinterpretation of radiographs (which is closely related but not necessarily the same as diagnostic errors). The only previous report of all errors in an A\&E department was a description of 135 diagnostic errors that occurred over six months. ${ }^{8}$ No study of missed radiographs has been longer than a year.

The aim of this study is to describe, in detail, the diagnostic errors occurring in an $A \& E$ department over a four year period.

\section{Method}

DEFINITION OF A DIAGNOSTIC ERROR

The definition of a diagnostic error was a diagnosis that could have been made in the $A \& E$ department but that was not made until after the patient left $A \& E$.

It excluded

- Patients in whom a diagnosis was missed by an SHO but made by a more senior doctor before the patient left the department.

- Diagnoses of, for example, "probable fracture" or "possible fracture" were excluded unless subsequent radiographs confirmed that there was a fracture.

- False positive diagnoses.

- Injuries missed because initial radiographs were normal were excluded. However, if these radiographs were of poor quality or the correct radiographic views had not been requested, patients were included. It is accepted that fractures of the scaphoid may have normal radiographs at presentation and that patients should be treated on clinical suspicion and so fractures of the scaphoid with normal initial radiographs that were missed because no follow up was organised were included. 
Table 1 Diagnostic errors made 1 August 1992 to 6 August 1996

\begin{tabular}{|c|c|c|c|c|}
\hline Diagnosis & $\begin{array}{l}\text { Number of } \\
\text { errors }\end{array}$ & $\%$ & $\begin{array}{l}\text { Number of } \\
\text { patients }\end{array}$ & $\%$ \\
\hline Fractures & 760 & 79.7 & 746 & 79.9 \\
\hline Dislocations & 19 & 2.0 & 19 & 2.0 \\
\hline Tendon injuries & 21 & 2.2 & 21 & 2.2 \\
\hline Nerve injuries & 5 & 0.5 & 2 & 0.2 \\
\hline $\begin{array}{l}\text { Ligament } \\
\text { injuries }\end{array}$ & 15 & 1.6 & 14 & 1.5 \\
\hline Foreign bodies & 19 & 2.0 & 19 & 2.0 \\
\hline Other trauma & 51 & 5.4 & 51 & 5.5 \\
\hline Non trauma & 36 & 3.8 & 36 & 3.9 \\
\hline \multirow{2}{*}{$\begin{array}{l}\text { Incidental } \\
\text { findings }\end{array}$} & 27 & 2.8 & 26 & 2.8 \\
\hline & 953 & & 934 & \\
\hline
\end{tabular}

Table 2 Primary reason for diagnostic error

\begin{tabular}{llr}
\hline Primary reason for error & $\begin{array}{l}\text { Number of } \\
\text { patients }\end{array}$ & $\%$ \\
\hline Abnormality missed on radiograph & 727 & 77.8 \\
Failure to radiograph & 125 & 13.4 \\
Wrong radiograph taken & 25 & 2.7 \\
Clinical error & 38 & 4.1 \\
Other & 19 & 2.0 \\
& 934 & \\
\hline
\end{tabular}

Table 3 Number of attendances at which diagnosis was missed

\begin{tabular}{llrl}
\hline Number of attendances & $\begin{array}{l}\text { Number of } \\
\text { patients }\end{array}$ & $\%$ & Notes \\
\hline 1 & 886 & 94.9 & \\
2 & 37 & 4.0 & \\
3 & 8 & 0.9 & \\
4 & 2 & 0.2 & (wooden FB) \\
13 & 1 & 0.1 & \\
& 934 & & \\
\hline
\end{tabular}

Table 4 Grade of most senior person making error at first visit

\begin{tabular}{lcc}
\hline Grade & $\begin{array}{c}\text { Number of } \\
\text { patients }\end{array}$ & $\%$ \\
\hline Consultant & 25 & 2.7 \\
Senior registrar & 9 & 1.0 \\
Registrar & 5 & 0.5 \\
Senior house officer & 797 & 85.3 \\
Clinical assistant & 10 & 1.1 \\
Locum & 72 & 7.7 \\
Radiologist & 2 & 0.2 \\
Medical SHO/registrar & 3 & 0.3 \\
Nurse practitioner & 1 & 0.1 \\
Unknown & 10 & 1.1 \\
& 934 & \\
\hline
\end{tabular}

In non-trauma patients (for example, myocardial infarction and causes of abdominal pain), diagnosis in $A \& E$ is more difficult and may need a period of observation and the results of further tests and many patients are admitted with a diagnostic label of, for example, "chest pain ?cause". Patients with such conditions were only included as having a diagnostic error if they had been discharged from hospital.

In all cases, where there was dispute over the diagnosis (for example, between clinician and radiologist), the final decision was made by me (usually after discussion of the radiographs with a radiologist or at a departmental joint meeting with the radiologists).

DATA COLLECTION

Diagnostic errors were detected by a variety of means. The commonest ways were:

- After receipt of a radiological report
Table 5 How the correct diagnosis was made

\begin{tabular}{lrr}
\hline & $\begin{array}{c}\text { Number of } \\
\text { patients }\end{array}$ & \multicolumn{1}{c}{$\%$} \\
\hline After receipt of radiology report & 534 & 57.2 \\
In follow up clinic & 112 & 12.0 \\
Patient returned to A\&E & 72 & 7.7 \\
While an inpatient & 101 & 10.8 \\
By general practitioner & 25 & 2.7 \\
By other hospital department & 4 & 0.4 \\
By physiotherapist & 1 & 0.1 \\
At another hospital & 3 & 0.3 \\
While doing medicolegal report & 1 & 0.1 \\
After receipt of pathology report & 1 & 0.1 \\
After a complaint & 2 & 0.2 \\
Later review of radiographs & 1 & 0.1 \\
After a chance meeting with patient & 1 & 0.1 \\
Not recorded & 76 & 8.1 \\
& 934 & \\
\hline
\end{tabular}

- When patient attended an A\&E follow up clinic

- While patient was on the A\&E ward

- When the patient reattended $\mathrm{A} \& \mathrm{E}$ or was referred back by their general practitioner.

Other ways in which the correct diagnosis came to light were:

- After a complaint

- While reviewing notes of patients being entered into the UK Major Trauma Outcome Study.

- After receipt of discharge summaries.

Details of misdiagnoses were collected by the A\&E consultants, senior registrars and registrars and were given to me. The A\&E SHOs are asked to notify one of the A\&E consultants of any patients who they saw at a second visit who had had an injury missed at an earlier visit.

At the start of data collection, a consultant plastic surgeon with an interest in hand injuries, all the consultant orthopaedic surgeons, consultant radiologists and consultants in health care of the elderly were written to and asked to notify the A\&E consultants of any diagnostic errors made in the $\mathrm{A} \& \mathrm{E}$ department that came to their attention.

All details were entered by me into a computerised database.

The following data were collected for every patient who suffered a missed diagnosis:

- Date of initial attendance

- A\&E attendance number

- Age

- Initial diagnosis

- Missed diagnosis/diagnoses

- Type of misdiagnosis, for example, fracture, tendon injury, medical problem

- Site of misdiagnosis, for example, wrist, chest

- The primary reason why the error was made, for example, failure to radiograph, radiological abnormality missed. Other reasons were also noted. For example, a fractured calcaneum visible on ankle radiographs and missed was recorded as missed on radiograph: if it would have been seen more easily on calcaneal radiographs that were not performed, the fact that wrong radiographs were taken was recorded as a secondary cause.

- How the correct diagnosis was made, for example, after receipt of radiological report, error discovered at a follow up clinic 
Table 6 Injuries missed on radiograph

\begin{tabular}{|c|c|c|c|c|c|c|}
\hline Area & Fractures & Dislocation & Other & Specific injury & & Notes \\
\hline Shoulder & 23 & 3 & & Clavicle & 12 & \\
\hline \multirow{3}{*}{ Elbow } & 49 & & 24 & Radial head & 27 & \\
\hline & & & & Supracondylar & 12 & \\
\hline & & & & Haemarthrosis & 24 & \\
\hline Forearm & 2 & & & & & \\
\hline \multirow{4}{*}{ Wrist } & 109 & 1 & 5 & Distal radius & 24 & includes styloid and epiphysis \\
\hline & & & & Greenstick $(\mathrm{G} / \mathrm{S})$ radius & 46 & \\
\hline & & & & Scaphoid & 16 & includes tubercle \\
\hline & & & & Triquetrum & 12 & mostly chip \#s \\
\hline \multirow[t]{5}{*}{ Hand } & 143 & 2 & & Base of 5 th metacarpal & 12 & \\
\hline & & & & Other metacarpals & 12 & \\
\hline & & & & Thumb & 23 & \\
\hline & & & & Proximal phalanx of finger & 27 & $18 \mathrm{G} / \mathrm{S} \#$ \\
\hline & & & & Volar plate fracture & 31 & \\
\hline \multirow[t]{2}{*}{ Hip } & 31 & & & Neck of femur & 8 & \\
\hline & & & & One or more pubic rami & 17 & 2 pathological \\
\hline Femur & 2 & & & & 2 & \\
\hline Knee & 25 & & 2 & Tibial plateau & 10 & \\
\hline Leg & 2 & & & Tibia & 2 & \\
\hline \multirow[t]{3}{*}{ Ankle } & 108 & & & Lateral malleollus & 26 & 8 epiphyseal \\
\hline & & & & Calcaneum & 14 & \\
\hline & & & & Avulsion \#s & 55 & \\
\hline \multirow[t]{3}{*}{ Foot } & 62 & 2 & & Base of 5 th metatarsal & 14 & \\
\hline & & & & Other metatarsal & 24 & \\
\hline & & & & Toe & 24 & \\
\hline \multirow[t]{2}{*}{ Skull } & 17 & & & Linear skull \# & 15 & \\
\hline & & & & Compound depressed \# & 2 & \\
\hline \multirow[t]{3}{*}{ Spine } & 23 & & & Odontoid \# & 1 & \\
\hline & & & & Jefferson \# & 1 & \\
\hline & & & & Crush \# dorsal or lumbar spine & 12 & \\
\hline Face & 16 & & & Zygoma (including arch) & 11 & \\
\hline Chest and abdomen & 12 & & 1 & Liver laceration on computed tomography & 1 & \\
\hline
\end{tabular}

Table 7 Secondary reasons contributing to fractures missed on radiograph

\begin{tabular}{lll}
\hline Reason & Number & Notes \\
\hline Wrong radiographs taken & 34 & in 33 patients \\
Two fractures on one film —one diagnosed, another missed & 11 & Wrist 3, hand 4, knee 1, foot 2, chest 1. \\
Poor quality radiographs & 4 & 3 poor laterals, one overexposed \\
Abnormality seen and commented on but misinterpreted & 8 & \# 4th MT with callus diagnosed as exostosis \\
& & \# upper ulna interpreted as normal variant \\
& & Epiphyseal \# TP interpreted as chip \# \\
& New \# clavicle misinterpreted as old \\
& Skull \# as accessory suture \\
& \# lateral malleollus as accessory bone \\
& & \# base TP as sesamoid \\
& &
\end{tabular}

- Number of visits to A\&E before the correct diagnosis was made

- Name of the most senior doctor who missed the diagnosis

- Grade of the doctor (for example, consultant, SHO, locum)

- Where the doctor who missed the diagnosis was an SHO, their experience (that is, number of months in post) was noted.

- Whether any other department had also misdiagosed the patient, for example, radiologist, orthopaedic surgeons.

- Immediate action on discovering the diagnostic error, for example, send clinic appointment, notify GP

After 1993, for missed injuries the following information was also collected:

- AIS of the missed injury

- Misdiagnosis severity score (a measure of the severity of trauma diagnostic errors that scores errors on a scale of 1 to 7 based on the additional treatment that would have been given and the follow up that would have been done had the injury been correctly diagnosed initially). ${ }^{9}$

Derriford Hospital A\&E department is a busy department in a district general hospital with subregional specialties of neurosurgery and plastic surgery on site. During the time of
Table 8 Trauma abnormalities missed because of failure to radiograph

\begin{tabular}{lrll}
\hline & Fractures & Dislocations & Other \\
\hline Shoulder & 12 & & \\
Elbow & 6 & 1 & 2 \\
Wrist & 14 & 4 & \\
Hand & 12 & & \\
Hip & 8 & & \\
Knee & 10 & & \\
Leg & 5 & & \\
Ankle & 12 & & \\
Foot & 8 & & 5 \\
Spine & 11 & & \\
Chest & 9 & 5 & \\
Skull & 3 & & \\
Face & 7 & & \\
& 117 & & \\
\hline
\end{tabular}

the study the workload increased with the closure of another A\&E department in the city. At the start of the study it was staffed by two consultants, one or two senior registrars and eight SHOs. At the end of the study, the staffing was three consultants, two middle grade doctors (registrars or senior registrars) and 11 senior house officers (SHOs). All radiographs were reported by radiologists and after November 1994, many radiographs taken during normal working hours (Monday to Friday, 9 am to 5 $\mathrm{pm}$ ) were reported immediately. 
Table 9 Reasons for failure to radiograph fractures and dislocations

\begin{tabular}{lcl}
\hline Reason & Number & \\
\hline Other injuries elsewhere & 52 & \\
Other significant injury in same limb & 7 & \\
Poor localisation of injury & 14 & \\
Injury of contralateral limb & 5 & \\
Underestimate of injury & 46 & (\# odontoid in demented patient \\
No history of trauma & 2 & \# tibia in child ?NAI) \\
Patient violent and removed by police & 1 & (skull \#) \\
\hline
\end{tabular}

Table 10 Injuries missed because of poor clinical methods

\begin{tabular}{lcl}
\hline Injury & Number & Notes \\
\hline Closed tendon injuries & 12 & 6 Achilles tendon ruptures \\
Open tendon injuries & 9 & \\
Open nerve injuries & 3 & \\
Closed brachial plexus injury & 2 & \\
Closed ligamentous injuries & 15 & \\
& 41 & \\
\hline
\end{tabular}

Table 11 Incidental findings missed on radiograph

\begin{tabular}{|c|c|c|}
\hline Site & Abnormality missed & Notes \\
\hline \multicolumn{3}{|c|}{ Radiographs taken for trauma } \\
\hline \multirow[t]{2}{*}{ Shoulder } & Soft tissue calcification & \\
\hline & Pleural effusion (seen on shoulder radiograph) & \\
\hline \multirow[t]{2}{*}{ Elbow } & Old \# upper ulna (child, suspicion of NAI) & \\
\hline & Loose bodies & \\
\hline \multirow{2}{*}{ Wrist } & Non-union \# scaphoid & \\
\hline & Kienbocks disease of lunate & \\
\hline Hip & Perthes disease & \\
\hline \multirow{3}{*}{ Knee } & Loose bodies $\times 3$ & \\
\hline & Osteochondritis dissicans $\times 4$ & \\
\hline & Pellegrini Steida disease & \\
\hline Ankle & Hypertrophic pulmonary osteoarthropathy & \\
\hline \multirow[t]{4}{*}{ Spine } & Spondylolisthesis $\times 4$ & \\
\hline & Spondylolysis & \\
\hline & Congenital hemivertebra and scoliosis & \\
\hline & Scheuermans disease & \\
\hline Chest & Consolidation right middle lobe & \\
\hline \multirow[t]{2}{*}{ Skull } & Intracranial calcification & \\
\hline & Glass foreign body in scalp & \\
\hline \multicolumn{3}{|c|}{ Radiographs taken for non-trauma } \\
\hline Foot & Stress fracture 5 th metatarsal & (Taken to exclude osteomyelitis) \\
\hline
\end{tabular}

Results

Data were collected on injuries missed between 1 February 1992 and 6 August 1996. A total of 953 diagnostic errors were recorded in 934 patients. The types of diagnostic errors are shown in table 1 and the main reasons for error in table 2. Most errors were detected after a single visit but the number of attendances at which the error was missed is shown in table 3. The grade of the most senior person making the diagnostic error at the first visit is shown in table 4 . The way the diagnosis was finally made is shown in table 5 .

ABNORMALITIES MISSED ON RADIOGRAPHY

The main reason for diagnostic error in trauma patients was that abnormalities were missed on radiograph or computed tomography. The abnormalities missed were 624 fractures (in 618 patients), eight dislocations and 35 other abnormalities. The sites of these are shown in table 6 with details of the serious injuries missed and any individual injury missed on 10 or more occasions. Eighty five of the 624 missed fractures $(13.6 \%)$ were identified as greenstick fractures and $27(4.3 \%)$ as epiphyseal fractures. Secondary reasons to explain why abnormalities were missed are shown in table 7 .
In 25 diagnostic errors (in 24 patients) the diagnosis was also missed in whole or in part by a radiologist $(3.4 \%$ of injuries missed on radiography). In addition one patient had a wedge fracture of T11 missed because of failure to radiograph: the patient was later sent for a radiograph by their general practitioner and the radiograph was reported as normal, the fracture being diagnosed a year later when the radiographs were reviewed for the purposes of a medicolegal report.

INJURIES MISSED BECAUSE OF FAILURE TO RADIOGRAPH

The abnormalities missed in trauma patients because of failure to radiograph were 117 fractures (in 110 patients), five dislocations and five other injuries (table 8). Reasons for failure to radiograph are shown in table 9.

WRONG RADIOGRAPHS

In 16 missed fractures and six missed dislocations the primary reason for the error was that the wrong radiographs had been taken and that the injury was either not visible on the radiograph or was very difficult to see. In addition, $38(5.2 \%)$ of the abnormalities missed on radiograph, while easily visible on the radiograph, would have been seen more easily had correct views been taken.

OTHER REASONS FOR MISSED FRACTURES

It is recognised that a percentage of scaphoid fractures are not shown on plain radiographs initially but may be demonstrated on radiographs taken after an interval or by using other imaging techniques. In this series, two scaphoid fractures were missed because patients with normal scaphoid radiographs were not followed up.

MISSED TENDON, NERVE AND LIGAMENT INJURIES Twelve closed and nine open tendon injuries, five missed nerve injuries and 10 ligamentous injuries missed on clinical examination are shown in table 10 .

FOREIGN BODIES

Eighteen foreign bodies in wounds and one in the oesophagus were missed. Thirteen were missed on radiograph.

\section{INCIDENTAL FINDINGS}

Twenty seven significant incidental abnormalities (in 26 patients) were missed on radiographs taken for other reasons. These are shown in table 11 .

NON-TRAUMA

Thirty six non trauma diagnostic errors were made. These are shown in table 12 .

DEATHS

There were three known deaths in the series $(0.32 \%$ of patients). These are shown in table 13. In none can the diagnostic error in $A \& E$ be said to be the sole reason of death but it is clear that the error was an avoidable factor. In all three, errors were also made by other doctors 
Table 12 Missed non-traumatic problems

\begin{tabular}{|c|c|c|c|}
\hline Site & Missed diagnosis & Diagnosed as & Notes \\
\hline \multicolumn{4}{|l|}{ Missed on radiograph } \\
\hline Shoulder & Non-union \# clavicle and calcific tendinitis & Frozen shoulder & \\
\hline Elbow & OA and effusion & Strain triceps & \\
\hline Hand & Septic arthritis DIP joint & Soft tissue infection & \\
\hline Hip & Multiple metastases pelvis (Ca breast) & Bruise hip & \\
\hline \multirow[t]{4}{*}{ Knee } & Loose bodies $\times 3$ & OA knee & One subtle but shown \\
\hline & & Pain ?strain & better later on \\
\hline & & Monoarthritis knee & intercondylar view \\
\hline & Chondrocalcinosis (in pseudogout) & Effusion ?cause & \\
\hline \multirow[t]{2}{*}{ Foot } & Stress \# 2nd metatarsal & Swelling ?cause & \\
\hline & Stress \# 3rd metatarsal & Pain foot ?cause & \\
\hline Neck & Prevertebral surgical emphysema & Neck strain & \\
\hline Spine & Spondylolysis & Back pain & \\
\hline \multirow{10}{*}{ Chest } & Consolidation/infection $\times 6$ & Faint & \\
\hline & & Chest wall pain & \\
\hline & & Cough/emphysema & \\
\hline & & Viral pleuritis & \\
\hline & & Pleuritic pain ?cause & \\
\hline & & Costochondritis & \\
\hline & Other shadowing ? $\mathrm{Ca} \times 2$ & Collapse ?cause & \\
\hline & & Mechanical back pain & \\
\hline & Pneumothorax $\times 2$ & Chest infection & \\
\hline & & Epigastic pain ?gastritis & \\
\hline Head & Subarachnoid haemorrhage (missed on computed tomography) & Migraine & \\
\hline \multicolumn{4}{|c|}{ 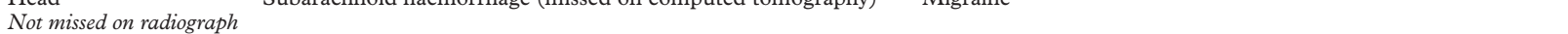 } \\
\hline Arm & Small cell sarcoma & Haematoma & \\
\hline \multirow[t]{2}{*}{ Hand } & Trigger thumb $\times 2$ & Soft tissue injury & \\
\hline & & Osteoarthritis & \\
\hline \multirow[t]{4}{*}{ Chest } & Myocardial infarction $\times 2$ & Both diagnosed as oesophageal pain & \\
\hline & Pneumothorax & Chest pain ?cause (failure to radiograph) & \\
\hline & Pulmonary embolus & Asthma & \\
\hline & Pneumonia & Febrile convulsion (failure to radiograph) & \\
\hline Spine & Spasmodic torticollis & Neck sprain & \\
\hline \multirow{2}{*}{ Overdose } & Overdose valproate & Hysterical and social problems & \\
\hline & Overdose carbamezepine & Head injury & \\
\hline \multirow[t]{2}{*}{ Skin } & Squamous cell carcinoma scalp & Seborrhoeic wart & \\
\hline & Myasis (tumbu fly) & Cellulitis & \\
\hline
\end{tabular}

Table 13 Deaths after diagnostic error

\begin{tabular}{ll}
\hline Initial diagnosis & Final diagnosis \\
\hline Asthma & Pulmonary embolus \\
Unconscious ?overdose & Extradural haematoma \\
Haematoma arm & Small cell sarcoma \\
\hline
\end{tabular}

(general practitioners in two cases, hospital doctors in one case).

\section{COMPLAINTS}

Twenty two complaints or legal cases resulted from the diagnostic errors $(2.4 \%$ of patients who had had an error made). Nine of 115

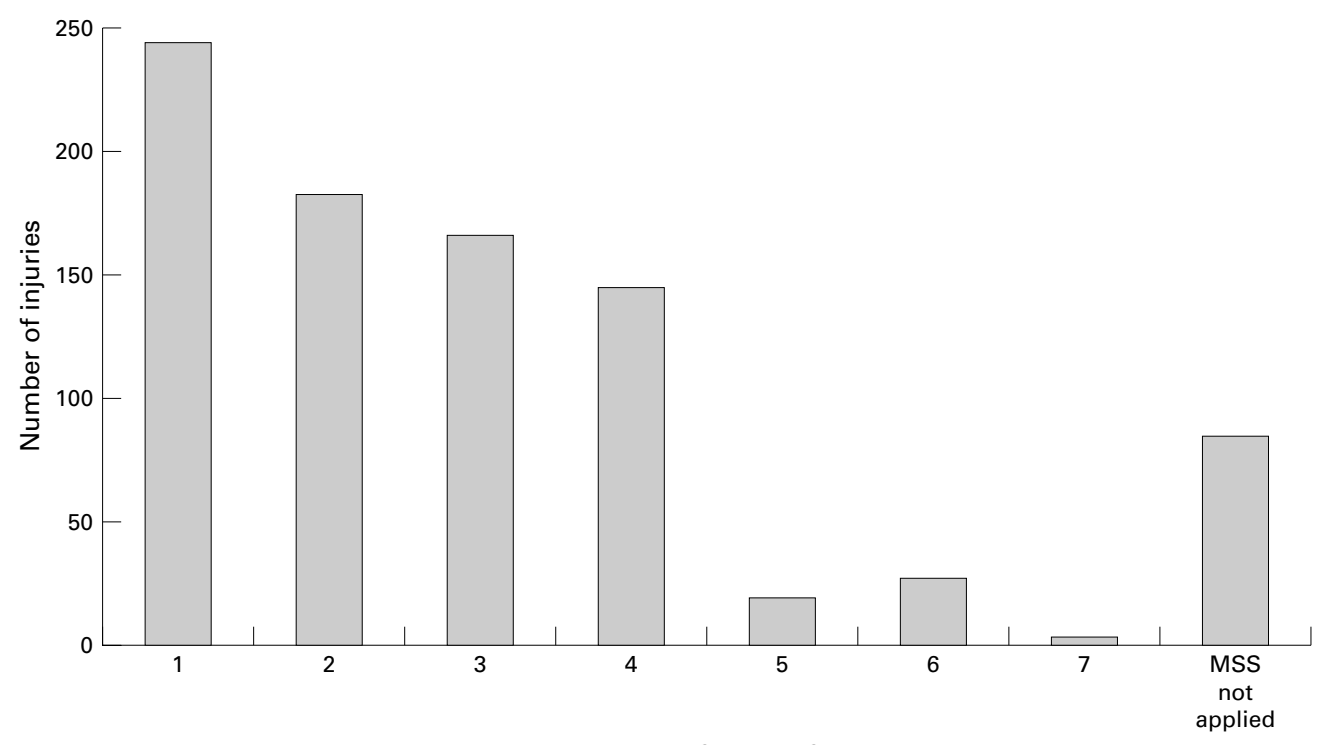

Misdiagnosis Severity Scores patients with injuries missed because of failure to radiograph complained compared with 7 of 626 with fractures and dislocations missed on radiograph, $\mathrm{p}=0.001$ ( $\chi^{2}$ test) .

SEVERITY OF DIAGNOSTIC ERRORS

The Misdiagnosis Severity Score (MSS) was developed during the collection of data and was only applied to injuries after 1 February 1993. From 1 February 1993 to 6 August 1996, 838 patients had diagnostic errors made. Altogether 787 diagnostic errors in 770 patients had a MSS applied. These are shown in figure 1 .

Figure 1 Misdiagnosis Severity Scores of injuries 1 February 1993 to 6 August 1996. 


\section{Discussion}

It is probably impossible to detect every diagnostic error and so this series is inevitably incomplete. My definition of a diagnostic error as a diagnosis that could have been made in the A\&E department but that was not made until after the patient left $A \& E$, is probably the only reasonable definition but it allows for some interpretation. Non-trauma diagnostic errors are difficult to define as noted above and this study almost certainly underestimates the number of such errors but I have included all those notified to me to try to give as accurate a picture as possible. It is also recognised that soft tissue knee injuries are difficult to fully diagnose clinically at an initial visit and this study does not include any isolated cruciate or meniscal tears though some must have been missed.

Some errors may not have been discovered. If a patient with a fracture was not radiographed or if a fracture was missed on radiograph by both $\mathrm{A} \& \mathrm{E}$ doctor and radiologist, the misdiagnosis would only come to light if the patient sought further medical help. This might not occur if the injury was minor. Other errors may have been discovered but not brought to the attention of the A\&E consultants. Devon is a holiday area and some patients may have had an error made while on holiday and then had the correct diagnosis made after their return home. Other patients may have had a correct diagnosis made by their general practitioner who did not inform us or may have attended a neighbouring A\&E department. ${ }^{10} \mathrm{It}$ is quite possible that some patients who had a diagnosis corrected within the department or hospital were not notified to me. In particular only four of the errors were identified because I was informed about them by another department within the hospital whereas a study of 250 consecutive referrals to a fracture clinic found that $17.2 \%$ of patients had had an incorrect diagnosis made. ${ }^{11}$ Many of these were false positive diagnoses but $3.6 \%$ had a misdiagnosis and were mistreated (but some of the initial diagnoses were of soft tissue injuries and would, in this hospital, have been referred to one of the $\mathrm{A} \& \mathrm{E}$ follow up clinics where the correct diagnosis could have been made rather than a fracture clinic).

No study can accurately detect all diagnostic errors and this information is the best that could be obtained.

The majority of errors were made by SHOs but these doctors see the majority of new patients and it is not possible from these data to compare the incidence of errors made by SHOs and more senior doctors. Many of the errors attributed to more senior doctors were made on patients seen by SHOs who showed the radiographs to a more senior doctor for a second opinion.

As in a previous series of diagnostic errors from the same department in $1981,{ }^{8}$ the main cause of diagnostic error $(77.8 \%)$ was failure to interpret radiographs correctly and the pattern of diagnostic errors and the way in which the true diagnosis comes to be made has, unfortunately, changed little since 1981 . The majority of the diagnoses missed on radiography were fractures. Some of the radiological abnormalities were subtle and radiologists missed abnormalities in $3.4 \%$ of these cases but the majority were obvious and this must indicate lack of teaching and/or poor technique in radiological interpretation. Some of the fractures had been seen and misinterpreted as normal variants or old injuries (more abnormalities may have been seen and misinterpreted without it being recorded). The large number of missed greenstick fractures must indicate that A\&E SHOs have not been taught to recognise this injury.

In a year's study of radiological misinterpretation in an A\&E department Wardrope and Chennells ${ }^{12}$ found that the commonest significant fractures missed on radiograph were undisplaced greenstick fractures of the wrist and fractures of the scaphoid, zygoma, skull and radial head. These were all commonly missed in this series. Others have written about difficulties in diagnosing skull fracture $\mathrm{s}^{13-15}$ and scaphoid fractures ${ }^{16}$ and many of the other abnormalities missed on radiograph have been reviewed. ${ }^{17}$

In $5.4 \%$ of fractures missed on radiograph the radiological interpretation was more difficult because the wrong radiographs were requested and in $2.1 \%$ of missed fractures and $32 \%$ of missed dislocations this was the major reason for the diagnostic error. It is important that the patient is properly examined to correctly identify the injured part and that doctors either take more care in either specifying the exact radiographic views that they wish to be taken (for example, for finger injuries, asking for finger radiographs rather than hand radiographs) or that they state exactly the injury that they wish to exclude so that radiographers can do the correct views (for example, a request stating "?dislocation acromioclavicular joint-radiograph of the shoulder please" should cause the radiographer to do acromioclavicular views even though they have not been specifically requested).

A good clinical examination should also reduce the number of fractures and dislocations missed because of failure to radiograph The decision on whether to radiograph a patient may be based on guidelines or on a doctor's experience but depends on the findings of a history and physical examination. Injuries missed because of failure to radiograph frequently occurred either because the injury was poorly localised or because of other injuries that serve to distract attention from an injured part. One injury in a limb will cause difficulties in examining the rest of the limb for further injuries. The full examination of a joint includes the examination of the joint above and the joint below as this will avoid many of these diagnostic errors. If the decision not to radiograph a limb is based on good clinical evidence any fracture missed will be minor. ${ }^{18}$

In this series $7.8 \%$ of injuries missed because of failure to radiograph resulted in a complaint or medicolegal claim compared with only $1.1 \%$ of injuries missed on radiograph. This difference is statistically highly significant. Although numbers are small, $22.2 \%$ of the missed open 
tendon injuries resulted in a complaint or medicolegal claim. It is probable that the reason for the difference is that most abnormalities missed on radiograph were discovered either after a radiological report or at a clinic review. The error was thus quickly identified allowing doctors to treat where required and to apologise. Injuries missed because of failure to radiograph and other clinical errors (for example, tendon injuries) will usually only be discovered and rectified if the patient initiates a further consultation. The vast majority of errors do not result in complaints at present but with increasing complaints and litigation, the high number of errors is a cause for concern.

How can the system be improved?

In the short-term, teaching should be improved and guidelines on the use of $\mathrm{A} \& \mathrm{E}$ radiology have been published. ${ }^{19}$ However, this cannot be expected to eliminate errors and it is important to develop fail safe mechanisms to detect errors when they occur. Radiology departments should give priority to reporting $\mathrm{A} \& \mathrm{E}$ films and the best solution is to have an immediate reporting system. ${ }^{20}$ Marking of abnormal radiographs by radiographers can assist in reducing diagnostic error ${ }^{21}$ but the value of this may be limited by a high rate of false positives. ${ }^{22}$

Better checks should reduce the number of diagnostic errors caused by misreading radiographs but it would be better to avoid such errors completely. Better checks will not reduce errors caused by failure to radiograph or other clinical errors and as this type of error is more likely to result in a complaint or legal action, it may be considered more serious than misreading radiographs. In the longer term, if diagnostic errors are to be reduced, the system should change to allow patients to be seen by better trained doctors. Radiology trainees have specific training in the interpretation of radiographs and then work under supervision before being allowed to interpret radiographs unsupervised. Junior doctors in A\&E should also, ideally, receive specific training and be tested on their ability to request and interpret radiographs correctly before being allowed to work unsupervised. This is not practical with current methods of staffing. It has been stated that is is unwise to roster an SHO for night duty during their first week in $\mathrm{A} \& \mathrm{E} .{ }^{23}$ Even this would be difficult to organise for many $A \& E$ departments and there is a need to increase the level of middle grade and senior cover in $\mathrm{A} \& \mathrm{E}$ departments to allow more patients to be seen by more experienced doctors and for better supervision of more junior doctors.

1 Vincent CA. Research into medical accidents: a case of negligence? BMF 1989;299:1150-3.

2 Richmond PW, Evans RC. Complaints and litigation - three years experience at a busy accident and emergency departyears experience at a busy accident and emergency department $1983-85$

3 Smith R. The epidemiology of malpractice. BMf 1990;301: $621-2$.

4 Rawlings ID. The management of dislocations of the carpal lunate. Injury 1981;12:319-30.

5 Henderson JJ, Arafa MAM. Carpometacarpal dislocations: an easily missed diagnosis. F Bone foint Surg 1987;69B: 212-14.

6 Guly HR. Missed tendon injuries. Arch Emerg Med 1991;8: 87-91.

7 Anderson ID, Woodford M, de Dombal FT, et al. Retrospective study of 1000 deaths from injury in England and Wales. BMF 1988;296:1305-8.

8 Guly HR. Missed diagnoses in an accident and emergency department. Injury 1984;15:403-6.

9 Guly HR. A scale for measuring the severity of diagnostic Guly HR. A scale for measuring the severity of diagnostic
errors in accident and emergency departments. $\mathcal{F}$ Accid Emerg Med 1997;14:290-2.

10 Guly HR, Grant IC. Patients who attend two accident and emergency departments. F Accid Emerg Med 1994;11:2313.

11 Morton RJ. Fracture clinic referrals: the need for self audit. Injury 1988:19:77-8.

12 Wardrope J, Chennells PM. Should all casualty radiographs be reviewed? BMF 1985;290:1638-40.

13 Gorman D. The utility of post traumatic skull Xrays. Arch Emerg Med 1987;4:141-50.

14 Vincent CA, Driscoll PA, Audley R, et al. Accuracy of detection of radiographic abnormalities by junior doctors. Arch Emerg Med 1988;5:101-9.

15 Royal College of Radiologists Working Party. Costs and benefits of skull radiography for head injury. Lancet 1981;ii:791-5.

16 Leslie IJ, Dickson RA. The fractured scaphoid. Natural history and factors influencing outcome. F Bone foint Surg 1981;63B:225-30

17 Guly HR. Diagnostic errors in trauma care. Bristol: Clinical Press, 1992.

18 Guly HR. Fractures not Xrayed. Arch Emerg Med 1986;3: $159-62$.

19 Touquet R, Driscoll P, Nicholson D. Teaching in accident and emergency medicine: 10 commandments of accident and emergency radiology. BMf 1995;310:642-5.

20 Craig JOMC. Litigation in clinical radiology. In: Powers MJ, Harris NH, eds. Clinical negligence. 3rd ed. London: Butterworths, 2000.

21 Berman L, de Lacey G, Twomey E, et al. Reducing errors in the accident and emergency department: a simple method using radiographers. $B M \mathcal{F}$ 1985;290:421-2.

22 Renwick IGH, Butt WP, Steele B. How well do radiographers triage $\mathrm{x}$ ray films in accident and emergency departments? BMF 1991;302:568-9.

23 Touquet R, Fothergill J, Fertleman M, et al. Ten clinical governance standards for Accident and Emergency departments. Clinical Risk 1999;1:44-9. 